\title{
El sueño de la inmortalidad: ¿eterna juventud o eterna decrepitud?
}

\author{
Lioba Simon Schuhmacher \\ Universidad de Oviedo
}

Resumen

El deseo de alcanzar la inmortalidad, y como paso previo la longevidad, se perfila a lo largo de todas las épocas y en las culturas más variadas. El presente artículo propone un cotejo de opiniones de autores dieciochescos españoles como Cadalso y Feijoo, y de autores ingleses como Johnson y Swift. Para ampliar la perspectiva se alude a puntos de vista de otros autores (Bacon, Hume, Boswell, Goethe o Sartre), y a modo de amenizarlo se observa cómo el tema es tratado en los medios de comunicación actuales (publicidad, prensa o cine). La parte propiamente analítica se centra en la feroz crítica satírica que realiza Jonathan Swift en el tercer libro de su famosa obra «Los Viajes de Gulliver» (1726), donde visita la comunidad de los Struldbruggs, y acaba dejando en evidencia la irracionalidad de esta aspiración humana.

Inmortalidad: calidad de inmortal, que no puede morir, que dura tiempo indefinido. Duración indefinida de una cosa en la *memoria de los hombres. ${ }^{1}$

El deseo de alcanzar la inmortalidad se perfila a lo largo de todas las épocas y en las culturas más variadas. La longevidad es un paso previo en el camino

${ }^{1}$ Diccionario Ideológico de Julio Casares, Barcelona, Editorial Gustavo Gili, S.A., 1979.

Cuadernos de Estudios del Siglo XVIII, núms. 10-11. Oviedo, Instituto Feijoo de Estudios del Siglo XVIII, Universidad de Oviedo, 2002, págs. 175-186. 
hacia ese viejo sueño de la humanidad. A lo que antes se aspiraba mediante el milagro y la intervención divina, hoy — y arrancando desde la época de las lucesse pretende conseguir mediante los avances de la ciencia. En los últimos tiempos los medios de comunicación se han hecho eco de los nuevos descubrimientos que vaticinan una longevidad sin los achaques de la vejez. Se habla de la hormona del crecimiento, de la dehidroepiandrosterona (DHEA), de la testosterona, de la melatonina o de antioxidantes.

Sin embargo, a pesar de que los mayores son un público con creciente poder adquisitivo, la publicidad sigue dirigida sobre todo a los jóvenes o a las personas de mediana edad, según lo expresa Antonio Muñoz Molina: «En los anuncios, la utopía se ha cumplido: nadie tiene más de treinta años»². La idealización de la juventud va ligada a la devaluación de la vejez. Se ensalzan los ideales de belleza típicos de la edad temprana: la piel tersa, la figura esbelta y el porte ágil. Los viejos suelen quedar relegados a un plano secundario en la publicidad, que se dirige a ellos sobre todo con productos como gafas graduadas, fijadores de dentaduras postizas, aparatos ortopédicos y fármacos. Se les presenta como seres con achaques, de los cuales hay que compadecerse (por ejemplo una Caja de Ahorros anima a abrir cuentas de las cuales un porcentaje - mínimorecaerá en una fundación para combatir el Alzheimer), o como seres prescindibles (como la abuela que es arrojada por su nieto por la ventana en cuanto éste descubre una fabada en lata igual de buena que la de ella).

A una persona de 60 años se le llega a nombrar «anciano», como sinónimo de decrépito. Según constata José Manuel Ribera, presidente de la Sociedad Española de Geriatría y Gerontología, «el diccionario ofrece 22 sinónimos de la palabra viejo, y 33 de la palabra anciano, todos ellos peyorativos, lo que da una idea del concepto que tenemos de nuestros mayores» ${ }^{3}$. Y entrando en el terreno de los «chistes», como aquel que promete una prima del seguro por cada anciano que es atropellado, se traspasa el umbral de lo morboso.

En la sociedad preindustrial y rural los mayores eran integrados en la gran familia, donde convivían tres y a veces cuatro generaciones, y cada miembro tenía su lugar. Los viejos eran venerados por los jóvenes, y se cuidaba de ellos hasta su muerte, que podía acontecer un achaque menor como un pequeño catarro o una caída sin importancia. En todo caso, muy pocos llegaban a muy mayores.

El «problema» actual consiste en que, gracias a los avances científicos, viven cada vez más tiempo. Cualquier achaque y numerosas enfermedades antes mor-

\footnotetext{
${ }^{2}$ Antonio Muñoz Molina, Eterna senectud, «El País Semanal», Madrid, 22-4-2001.

${ }^{3}$ Citado en $A B C$, Suplemento «Salud», pág. 14, Madrid, 13 de mayo de 2001.
} 
tales ahora son superables o se pueden mitigar. Por otra parte, las condiciones de vida laboral y social son tales que los mayores apenas tienen cabida en la familia nuclear y es preciso organizarse para cuidarlos. Las residencias para la tercera edad son sus nuevas guaridas, y la geriatría es una disciplina en auge. El efecto del envejecimiento de la población sobre la economía, en especial sobre el sistema de pensiones, hace que cunda la alarma entre los políticos, entre ellos Helmut Kohl, quien, siendo canciller de Alemania, planteó la situación con crudeza: ¿Cómo se puede sostener una sociedad donde buena parte de la población estudia hasta entrados en los treinta, se (pre-)jubila a los cincuenta y vive más allá de los ochenta?

En reiteradas ocasiones la literatura ha tratado el tema de la prolongación de la vida o de la vida eterna. Algunos de sus grandes mitos encarnan personajes que desafían el orden natural (o divino) y aspiran a la inmortalidad. Por ejemplo, Fausto pacta con el diablo, vendiendo su alma por rejuvenecer. El Dorian Gray de Oscar Wilde es otra de las figuras que personifican el mito de la eterna juventud, en la belleza incorrupta de un «dandy». El cine también ha tocado el tema una y otra vez. Por ejemplo, en las versiones de Drácula, o en la película Death becomes her ${ }^{4}$, donde la actriz Meryl Streep bebe del agua de la vida y logra burlar la muerte. El músico Michael Jackson persigue el deseo de permanecer eternamente joven, sometiéndose a la cirugía (anti-) estética, a burbujas de oxígeno y al aislamiento de los demás por temor a contagios.

Sin embargo, estos personajes, ficticios o reales, acaban pagando por su vanidad y su desafío a las reglas divinas o naturales. No consta ninguna historia de este tipo donde el final sea eternamente feliz. En las distintas versiones del Fausto, éste vuelve a su anterior estado, amén de causar grandes penurias a los demás (sobre todo a Gretchen, en la famosa versión de Goethe ${ }^{5}$ ). En el Nosferatu de Fritz Murnau, el vampiro aparece como un ser del cual sólo podemos sentir compasión: le aterra el aburrimiento eterno, el tener que repetir los mismos actos día tras día (o noche tras noche). En la película ya mencionada, Death becomes her, la protagonista no morirá, pero al precio de la histeria permanente, de constantes y tortuosas cirugías plásticas y de intrigas sin fin. Uno de los personajes principales de esta rocambolesca comedia renuncia a beber aquel agua y es presentado como el más feliz, precisamente en el día de su funeral. En el caso de Michael Jackson no es difícil vaticinar que sus mutaciones no le proporcionarán la vida eterna o la felicidad.

\footnotetext{
${ }^{4}$ La muerte le sienta tan bien.

${ }^{5}$ Johann Wolfgang von Goethe, Faust. Eine Tragödie. Erster und zweiter Teil, 1831, München, dtv Klassik, 1977; versión española: Johann W. Goethe Obras Completas, III. Fausto. Recopilación, traducción, estudio preliminar, preámbulo y notas de Rafael Cansinos Assens, Madrid, Aguilar, 1951.
} 
Considerar la muerte como algo natural, e incluso valorar el momento, no es frecuente. En la película Forrest Gump hay una escena enternecedora, cuando Forrest acude a casa de su madre enferma y le pregunta incrédulo: «Mamá, ¿qué te pasa?, ésta le contesta con serenidad y sin dramatismo: «My time has come» ${ }^{6}$. Y entrando en el escabroso terreno de desear la muerte de alguien, el suicidio o la eutanasia, recordemos a Jean Paul Sartre, que en sus escritos autobiográficos titulados Las Palabras, expresa su satisfacción por la —para éloportuna muerte de su padre: «No basta morir. Hay que morir a tiempo». ${ }^{7}$

Existen muchas formas de prolongarse, de dejar huella de la existencia propia o de «eternizarse». La más obvia es tener descendencia, que es, según Francis Bacon (1561-1626) la opción de la gente corriente, o los que se asemejan a «las bestias», los que no pueden hacerlo a través de cauces más nobles, como obras de caridad o escribir un libro:

La continuidad por procreación es común a las bestias; mientras que la memoria, el mérito y las nobles obras son propios de los humanos. Y es un hecho que las obras y las fundaciones más nobles proceden de hombres sin hijos, que han procurado expresar las imágenes de su mente donde las de su cuerpo han fallado. De este modo la posteridad está asegurada más en aquellos que no tienen posteri$\mathrm{dad}^{8}$.

La idea de la perpetuidad a través de la fama póstuma es un tema recurrente. Muchos escritores han presentado la vida eterna espiritual, a través de la fama póstuma como alternativa a la vida eterna física. Volviendo a la referencia del principio, recordemos que el término «inmortalidad» también puede significar «duración indefinida en la memoria».

En sus Cartas Marruecas ${ }^{9}$, José Cadalso pone en boca (o pluma) de Gazel la pregunta a Ben Beley sobre la fama póstuma « ¿Será, acaso, la quinta esencia de nuestro amor propio este deseo de dejar nombre a la posteridad? $\gg^{10}$. En su razonamiento, Gazel (o Cadalso) llega a la conclusión de que este deseo responde a la vanidad, al orgullo del ser humano, que con la muerte se ve abo-

${ }^{6}$ Ha llegado mi hora.

${ }^{7}$ Jean Paul Sartre, Les Mots / Die Wörter (1964), pág. 12, Rowohlt, 1976.

${ }^{8}$ Francis BACON, «Of Parents and Children», en: The Essays or Counsels Civil and Moral (1625), ed. de Brian Vickers, 1999, Oxford World's Classics, 1999. "The perpetuity by generation is common to beasts; but memory, merit, and noble works are proper to men. And surely a man shall see the noblest works and foundations have proceeded from childless men; which have sought to express the images of their minds, where those of their bodies have failed. So the care of posterity is most in them that have no posterity.»

${ }^{9}$ José Cadalso, Cartas Marruecas (1774), ed. de Joaquín Arce, Ediciones Cátedra, Madrid, 1978. Car$\operatorname{tas} n^{\circ} .27,28,84$ y 85

${ }^{10}$ Ibidem, 27, pág. 153. 
cado a renunciar a «todas las lisonjas recibidas mientras adquirió la fama.» $\mathrm{Y}$ se cuestiona: «¿por qué no he de vivir eternamente, dícese a sí mismo, recibiendo los aplausos que voy a perder? Voces tan agradables, ¿no han de volver a lisonjear mis oídos?...» ${ }^{11}$, para continuar:

Semejantes reflexiones le atormentan en la muerte; pero hace su último esfuerzo su amor propio, y le engaña diciendo: tus hazañas llevarán tu nombre de siglo en siglo a la más remota posteridad; la fama no se oscurece como el humo de la hoguera, ni se corrompe como el polvo del sepulcro. Como hombre te comprehende la muerte, como héroe la vences. Ella misma se hace la primera esclava de tu triunfo, y su guadaña el primero de tus trofeos. La tumba es una cuna de semidioses como tú; en su bóveda han de resonar las alabanzas que te canten futuras generaciones. Tu sombra ha de ser tan venerada por los hijos de los que viven como lo fue tu presencia entre sus padres. Hércules, Alejandro y otros ¿̨no viven? ¿̇Acaso han de olvidarse sus nombres? Con estos y otros iguales delirios se aniquila el hombre; muchos de este carácter inficionan toda la especie; y anhelan a inmortalizarse algunos que ni aun en su vida son conocidos ${ }^{12}$.

Ben Beley, en su respuesta a Gazel, concuerda en que el deseo de fama póstuma es una especie de locura:

Veo lo que me dices del exceso de amor propio, de donde nace esa necedad de querer un hombre sobrevivirse a sí mismo. Creo, como tú, que la fama póstuma de nada sirve al muerto, pero puede servir a los vivos con el estímulo del ejemplo que deja el que ha fallecido. Tal vez éste es el motivo del aplauso que logra.

En este supuesto, ninguna fama póstuma es apreciable sino la que deja el hombre de bien. [...] La fama póstuma del justo y bueno tiene otro mayor y mejor influjo en los corazones de los hombres, y puede causar superiores efectos en el género humano. Si nos hubiésemos aplicado a cultivar la virtud tanto como las armas y las letras, y si en lugar de las historias de los guerreros y los literatos se hubiesen escrito con exactitud las vidas de los hombres buenos, tal obra, jcuánto más provechosa sería ${ }^{13}$.

Mucho más adelante, en la carta 84, Ben-Beley retoma el tema de la fama póstuma, siendo irónicamente indulgente con esa aspiración humana:

${ }^{11}$ Ibidem, pág. 154.

12 Ibidem, pág. 154.

${ }^{13}$ Ibidem, págs. 155-156. 
Después de escribirte meses ha sobre este asunto, he considerado que el tal deseo es una de las pocas cosas que pueden consolar a un hombre de mérito desgraciado. Puede serle muy fuerte alivio el pensar que las generaciones futuras le harán la justicia que le niegan sus coetáneos, y soy de parecer que se han de dar cuantos gustos y consuelos pueda apetecer, aunque sean pueriles, como sean inocentes, al infeliz y cuitado animal llamado hombre ${ }^{14}$.

En su respuesta, Gazel cita a su amigo español, Nuño:

Ya es demasiado el número de gentes que en España siguen el sistema de la indiferencia sobre esta especie de fama. $\mathrm{O}$ sea carácter del siglo o espíritu verdadero de filosofía; o sea consecuencia de la religión, que mira como vanas, transitorias y frívolas las glorias del mundo, lo cierto es que en la realidad es excesivo el número de los que miran el último día de su vida como el último de su existencia en este mundo.

Para confirmarme en ello, me contó la vida que hacen muchos, incapaces de adquirir tal fama póstuma. No sólo hablo de la vida deliciosa de la corte y grandes ciudades, que son lugar común de la crítica, sino de las villas y aldeas. El primer ejemplo que saca es el del huésped que tuve y tanto estimé en mi primer viaje por la península. A éste siguen otros varios muy parecidos a él, y suele concluirse diciendo: - Son muchos millares de hombres los que se levantan muy tarde, toman chocolate muy caliente y agua muy fría, se visten, salen a la plaza, ajustan un par de pollos, oyen misa, vuelven a la plaza, dan cuatro paseos, se informan en qué estado se hallan los chismes y hablillas del lugar, vuelven a casa, comen muy despacio, duermen la siesta, se levantan, dan un paseo al campo, vuelven a casa, se refrescan, van a la tertulia, juegan a la malilla, vuelta en casa, rezan el rosario, cenan y se meten en la cama ${ }^{15}$.

La previsión de futuro de cara a la posteridad, dejar un recuerdo positivo o un ejemplo a seguir, son nobles aspiraciones. Por tanto, los que viven el día a día sin esas miras son considerados seres poco menos que vegetales.

Sin necesidad de pensar en el más allá, algunos escritores y filósofos dieciochescos recomiendan hacer acopio de saber, experiencias o buenas obras en la juventud para así poder disfrutar en la vejez de salud y de recuerdos loables. Así lo hace el moralista Samuel Johnson, en boca de su personaje Rasselas, que sale en busca de la felicidad. En este viaje simbólico por tierras de Egipto

\footnotetext{
${ }^{14}$ Ibidem, carta 84, pág. 289.

${ }^{15}$ Ibidem, carta 85, pág. 290.
} 
(el exotismo es recurso de moda en la literatura del siglo de las luces), el príncipe advierte a un grupo de jóvenes, «cuya sola ocupación es satisfacer sus deseos y cuyos días se pasan todos en continuo gozar», que «la felicidad debe ser algo sólido y permanente, sin temor y sin incertidumbre» ${ }^{16}$. Sigue en su arenga:

Los primeros años del hombre deben ser para prevenir los últimos. Quien nunca piensa, nunca será prudente. La frivolidad constante terminará siempre en ignorancia; y la intemperancia, aunque inflame el ánimo una hora, acortará la vida o la hará desgraciada. Pensemos que la juventud no dura mucho y que en la edad madura, cuando los encantos de la fantasía cesen y los fantasmas del deleite no bailen ya entre nosotros, no tendremos otro consuelo que la estima de los hombres sabios y la capacidad de hacer el bien. Detengámonos, por tanto, mientras está en nuestro poder detenernos; vivamos como hombres que se harán viejos y para quienes el más terrible de todos los males no será contar los años idos sólo por sus locuras, ni acordarse de su antigua lozanía sólo al ver los achaques que los excesos produjeron ${ }^{17}$.

Ya que los jóvenes, al escucharle, irrumpen en carcajadas, Rasselas, prosigue su búsqueda de la felicidad en otros lugares y en otras compañías.

El paso del tiempo, simbolizado muchas veces por un reloj que actúa como conciencia del carácter efímero del ser humano, es otro tema que abordan los escritores del siglo xvIII. Por ejemplo, el Padre Feijoo en sus Décimas a la conciencia en metáfora de reloj:

Conciencia, reloj viviente

Que en el espíritu humano

Fabricó con sabia mano

Artífice Omnipotente;

Pulsa, suena, indeficiente

Pues que sirve bien oída,

Esa máquina regida

En su más tranquila calma

De despertador del alma,

Y de muestra de la vida

$\cdots$

Tu aviso, con igualdad,

\footnotetext{
${ }^{16}$ Samuel Johnson, La historia de Rásselas, príncipe de Abisinia (1759), ed. y traducción de Pollux Hernúñez, Madrid, Alianza Editorial, 1991, pág. 80.

${ }^{17}$ Ibidem, pág. 81.
} 
Observaré diligente,

Sabiendo que está pendiente

Del tiempo la eternidad.

Y pues con tal brevedad

Vuela el día que me alienta,

Bienes adviertas, atenta,

Cuánto te importa, alma mía,

Tener cuenta con el día

Para el día de la cuenta ${ }^{18}$.

El más allá es un concepto que, quizás por primera vez, se ponía en cuestión en el siglo de las luces. Muchos ilustrados, sobre todo franceses y algunos ingleses, eran abiertamente ateos, y, en base a argumentos empíricos, refutaban la vida allende la muerte. El moribundo David Hume, fue «asediado» por el joven James Boswell (luego famoso como el biógrafo de Johnson), con preguntas sobre la inmortalidad. Boswell, sorprendido por la imperturbable serenidad con que el filósofo afrontaba la nada de la que estaba cierto, le insistió: «Pero, ¿no le gustaría a usted hallar a Fulano y Zutano, sus buenos amigos, en una vida futura?». Y Hume repuso tranquilamente: «Me sorprendería hallarlos allí porque ninguno creía en ella» ${ }^{19}$.

Sin embargo, y como hemos visto, a la mayoría de los mortales les resulta difícil asumir la finitud. La humanidad, a través de los tiempos, y en formas variadas, ha requerido explicaciones a la muerte, esquivarla, engañarla, y ha buscado no sólo la prolongación de la vida (con cada vez más éxito), sino la inmortalidad, es decir, la infinidad de la vida.

El maestro de la sátira del siglo XVIII, el anglo-irlandés Jonathan Swift, uno de los literatos más famosos de todos los tiempos y autor de una de las grandes obras de la literatura universal, Los viajes de Gulliver (1726), aborda este tema de una forma peculiar y original ${ }^{20}$.

En el capítulo 10 del tercer libro de Los viajes de Gulliver, en el imaginario lugar de Luggnagg, el curioso viajero Gulliver es informado de que allí «algunas veces, aunque muy escasas, acertaba a nacerle a una familia un niño con un lunar rojo en la frente, justo encima de la ceja izquierda, que era señal infa-

\footnotetext{
${ }^{18}$ Feijoo, Benito Jerónimo, Obra selecta. Prólogo y selección de textos por Eduardo Blanco-Amor, Santiago de Compostela, Edicións Sálvora, 1984 (Biblioteca de Autores Gallegos) págs. 430-431.

${ }^{19}$ Citado por Fernando Savater, en Boswell, El curioso impertinente, «El País», 9 de septiembre de 1995.

${ }^{20}$ Jonathan SwIFт, Los viajes de Gulliver (1726), ed. de Pilar Elena, trad. de Pollux Hernúñez, Madrid, Ediciones Cátedra-Letras Universales, 1992.
} 
lible de que nunca moriría». Dichos nacimientos son el resultado de la pura casualidad, y se trata de los «struldbruggs», o inmortales. La reacción de Gulliver, al enterarse de esa condición, es de euforia:

Confieso francamente que me embargó un gozo indescriptible al oír este relato, y $[\ldots]$ no pude evitar desahogarme con expresiones tal vez un poco disparatadas. Grité como extasiado: «iFeliz la nación en que cada niño puede al menos tener la suerte de ser inmortal! ¡Feliz el pueblo que disfruta de tantos modelos vivientes de antigua virtud y cuenta con maestros dispuestos a instruirlo en la sabiduría de las edades pretéritas! ¡Pero felicísimos sobre toda comparación son aquellos eximios struldbruggs que, nacidos sin las trabas de aquella universal fatalidad de la naturaleza humana, tienen el espíritu libre y desembarazado, sin el peso y el abatimiento de ánimo que causa el miedo continuo a la muerte!» (pág. 470).

Gulliver supone que esos inmortales son «consejeros tan sabios y capacitados» o «seres superiores». Se extraña de no haber visto ninguno en la Corte, y solicita ser recibido por ellos. Sin embargo, su interlocutor reacciona «con esa cierta sonrisa que suele nacer de la compasión hacia el ignorante» (pág. 471). Junto con sus contertulianos, su anfitrión insta a Gulliver a que relate «qué método habría yo seguido si me hubiera tocado la suerte de haber nacido struldbrugg.» (pág. 471). Y Gulliver se explaya, que en cuanto hubiese asumido esa su felicidad,

...primero me decidiría a procurarme riquezas por todos los medios y maneras posibles. En este empeño podría, lógicamente esperar que, con economías y administración, en unos doscientos años sería el hombre más rico del Reino. En segundo lugar, me dedicaría desde los primeros años de mi juventud al estudio de las artes y las ciencias, con lo cual llegaría alguna vez a ser superior a todos los demás en erudición. Finalmente, me ocuparía de registrar cuidadosamente todo acto o suceso de importancia que tuviera lugar en el estado, y describiría con mano imparcial los caracteres de los varios sucesores de soberanos y grandes ministros de gobierno, $[\ldots]$ Con todas estas adquisiciones sería un tesoro viviente de conocimientos y sabiduría, y sin duda vendría a ser el oráculo de la nación (págs. 471-472).

Es decir, y por este orden, Gulliver se procuraría una base material, después educación y estudios, y finalmente sería historiógrafo, o la conciencia viviente del pueblo. No se casaría (una muestra de la misoginia de Swift), pre- 
dicaría la virtud con el ejemplo, sería sociable y practicaría la caridad y la justicia. Sobre todo estaría «advirtiendo e instruyendo continuamente a la humanidad» (p. 472). Al término del discurso de Gulliver,

[...] hubo un buen rato de charla entre ellos en el idioma del país, sin que faltaran algunas risas a costa mía. Por fin, el mismo caballero que había hecho de intérprete dijo que los otros le pedían me corrigiera en unos errores en que había incurrido a causa de la imbecilidad propia de la naturaleza humana, y que por tal disculpa era yo menos responsable de ellos... (pág. 474).

El caballero, por sus propios viajes, conoce las ansias de la especie humana de vivir eternamente y sabe que en el mundo de Gulliver

el más anciano tenía esperanzas de vivir todavía un día más, y consideraba la muerte como el mal más grande ante el cual la Naturaleza le instaba siempre a retroceder; y que sólo en la isla de Luggnagg, la sed de vivir no era tan acuciante, por el continuo ejemplo de los struldbruggs que tenían ante los ojos (pág. 475).

Poco a poco el anfitrión va desencantando a Gulliver:

Añadió que el método de vida imaginado por mí era poco razonable e injusto, pues presuponía una juventud, salud y vitalidad eternas, que ningún hombre en su sano juicio podría esperar por muy descomedido que fuera en sus deseos. Que la cosa no era tanto la posibilidad de que un hombre eligiera permanecer siempre en la flor de la juventud, cortejado por la prosperidad y la salud, sino cómo pasaría una vida sin fin sometido a todos los inconvenientes que la ancianidad habitualmente conlleva (pág. 475).

Tras esta larga introducción, el caballero le habla detalladamente de los struldbruggs, relatando que se comportan igual que los mortales hasta aproximadamente los treinta años. Entonces les entra, poco a poco,

una tristeza y abatimiento que seguía aumentando hasta los ochenta. [...]. Cuando alcanzan los ochenta, que se considera la edad máxima de vida en este país, cuentan ellos no sólo con todas las memeces y achaques propios de otros viejos, sino también con muchas más derivadas de la espantosa perspectiva de no morir jamás. No sólo son obstinados, picajosos, codiciosos, hoscos, vanidosos y parlanchines, sino también nulos para la amistad e insensibles a todo afecto natural, que nunca se prolonga más allá de sus nietos. La envidia y los deseos que frustra la impotencia 
son sus pasiones predominantes. [...] ...se ven excluídos de toda posibilidad de placer, y cuando quiera que ven un funeral se lamentan y se afligen porque otros van a un puerto de descanso al que ellos nunca pueden tener la esperanza de arribar. [...] Los menos desgraciados de ellos parecen ser los que empiezan a chochear y pierden la memoria...

Y en otro alarde de misoginia, Swift explica que si un struldbrugg se ha casado con alguien de su misma condición, se le concede gentilmente la anulación del matrimonio en cuanto el más joven cumpliera los ochenta, «pues entiende la ley que es lógica indulgencia que aquellos que se ven condenados sin culpa de su parte a permanecer eternamente en el mundo, no deberían ver sus sufrimientos doblados con la larga carga de una esposa» (pág. 477).

Entonces también se les considera difuntos, sus herederos toman posesión de sus bienes y se les deja una renta miserable, siendo inhabilitados para cargos o responsabilidades. Y continúa:

A los noventa pierden la dentadura y el pelo, y a esa edad ya no distinguen entre un sabor y otro, sino que comen y beben lo que pueden obtener, sin gusto ni apetito. [...] Cuando hablan se olvidan de la denominación normal de las cosas y de los nombres de la gente, incluso de aquellos que son sus amigos y parientes más cercanos. Por la misma razón nunca pueden distraerse leyendo, pues la memoria no puede acompañarlos del principio al final de una frase, y por ese defecto se ven privados del único pasatiempo al que de otro modo podrían dedicarse (pág. 478).

Las desgracias no acaban ahí, pues no se pueden entender con nadie debido a que la lengua del país está continuamente cambiando y no tienen memoria. Finalmente, Gulliver es llevado a observar un grupo de struldbruggs, y se desconcierta porque éstos «no sintieron la mínima curiosidad por hacer pregunta alguna» (pág. 478). En fin, despreciados por todos, «ofrecían el espectáculo más humillante que nunca contemplé, y las mujeres eran más horribles que los hombres» (pág. 479). Todas estas revelaciones conducen a un radical cambio de actitud de Gulliver hacia el concepto de la inmortalidad:

Podrá fácilmente creer el lector que por lo que oí y vi, mi vivo deseo de una vida sin fin quedó muy malparado. Empecé a sentirme sinceramente avergonzado de las halagadoras fantasías que había imaginado y pensé que no habría tirano que inventara una muerte a la que no me lanzara con gusto por abandonar tal vida (pág. 479). 
El rey de Luggnagg se alegra de este cambio de actitud de Gulliver, y lamenta que no es posible enviar un par de struldbruggs a su país para pertrechar a la gente contra el temor a la muerte. Hemos visto como Swift desmonta, paso a paso, el ideal de la inmortalidad, desde el éxtasis inicial de Gulliver, observando a los inmortales, que no lo son en condición de jóvenes, sino de seniles, con todos los achaques que eso conlleva, y condenados así a la eternidad. De una forma sistemática e inteligente, el autor nos ha conducido a través de todas esas reflexiones, para llegar con nosotros a la revelación de que la muerte es un alivio y que deberíamos sentirnos felices por no ser inmortales.

En conclusión, y aplicando dichos mensajes a la actualidad, una forma de hacer frente a esta situación de decrepitud es preparar un catálogo de deseos para cuando llegue esa «última edad». Así lo sugiere el psicólogo Miguel Silveira $^{21}$. Entre dichos propósitos se encuentran los siguientes: no andar quejándose ni aburrir a la gente con las mismas historias, no ser gruñón ni cascarrabias ni tozudo, no dar que hacer a quien le cuide a uno, llevar los achaques con discreción, no abandonar el aspecto ni descuidarse, intentar ser amable y atractivo, irradiar jovialidad y entusiasmo, tener la mente activa y seguir aprendiendo, esquivar nostalgias del pasado, y finalmente, aceptar lo inevitable y querer morir con dignidad.

${ }^{21}$ Miguel Silveira, Cómo envejecer. Psicología de la vejez, obra en preparación, Barcelona, Editorial Alba, posiblemente: 2003 . 